\title{
Ion Trap Collision-Induced Dissociation of Human Hemoglobin $\alpha$-Chain Cations
}

\author{
Tegafaw T. Mekecha, Ravi Amunugama, and Scott A. McLuckey \\ Department of Chemistry, Purdue University, West Lafayette, Indiana, USA
}

\begin{abstract}
Multiply protonated human hemoglobin $\alpha$-chain species, ranging from $[\mathrm{M}+4 \mathrm{H}]^{4+}$ to $[\mathrm{M}+$ $20 \mathrm{H}]^{20+}$, have been subjected to ion trap collisional activation. Cleavages at 88 of the 140 peptide bonds were indicated, summed over all charge states, although most product ion signals were concentrated in a significantly smaller number of channels. Consistent with previous whole protein ion dissociation studies conducted under similar conditions, the structural information inherent to a given precursor ion was highly sensitive to charge state. A strongly dominant cleavage at $\mathrm{D}_{75} / \mathrm{M}_{76}$, also noted previously in beam-type collisional activation studies, was observed for the $[\mathrm{M}+8 \mathrm{H}]^{8+}$ to $[\mathrm{M}+11 \mathrm{H}]^{11+}$ precursor ions. At lower charge states, C-terminal aspartic acid cleavages were also prominent but the most abundant products did not arise from the $\mathrm{D}_{75} / \mathrm{M}_{76}$ channel. The $[\mathrm{M}+12 \mathrm{H}]^{12+}-[\mathrm{M}+16 \mathrm{H}]^{16+}$ precursor ions generally yielded the greatest variety of amide bond cleavages. With the exception of the $[\mathrm{M}+4 \mathrm{H}]^{4+}$ ion, all charge states showed cleavage at the $\mathrm{L}_{113} / \mathrm{P}_{114}$ bond. This cleavage proved to be the most prominent dissociation for charge states $[\mathrm{M}+14 \mathrm{H}]^{14+}$ and higher. The diversity of dissociation channels observed within the charge state range studied potentially provides the opportunity to localize residues associated with variants via a top-down tandem mass spectrometry approach. (J Am Soc Mass Spectrom 2006, 17, 923-931) (C) 2006 American Society for Mass Spectrometry
\end{abstract}

\section{$\mathrm{M}$} ass spectrometry has been applied to the characterization of hemoglobin and its variants for the past quarter of a century, beginning with the use of field desorption [1] and fast atom bombardment [2] as means for ionizing peptides derived from digestion. Today, applications of mass spectrometry to hemoglobin analysis generally employ either electrospray (ES) or matrix-assisted laser desorption ionization (MALDI) as the ionization method [3-15]. In the case of characterization of hemoglobin for clinical applications, the subunits of the tetrameric hemoglobin complex are generally subjected to analysis as individual polypeptides devoid of heme. The information of interest is generally the primary structure of one or more of the subunits. While the presence of significant abundances of a variant is commonly identified in screening applications via separation methods such as electrophoresis and liquid chromatography, such methods do not provide direct structural information. Likewise, while the measurement of the intact mass of a globin subunit is often sufficiently specific to provide identification, mass measurement alone does not provide primary structure information. Protein digestion followed by peptide mass mea-

Published online May 15, 2006

Address reprint requests to Dr. S. A. McLuckey, Department of Chemistry, 1393 Brown Laboratories, Purdue University, West Lafayette, IN 479071393, USA. E-mail: mcluckey@purdue.edu surement can often localize origins of amino acid substitutions associated with a variant. The application of tandem mass spectrometry to peptides derived from digestion is an alternative to the peptide mass mapping approach just mentioned. The application of such an approach for the rapid identification of $\alpha$-chain variants, for example, has been described [16, 17].

An important advantage of mass spectrometry over other approaches in use for screening clinical samples is speed. For this reason, it is desirable to employ methods that minimize sample preparation and separation steps while simultaneously maintaining a high degree of structural specificity. Perhaps the most structurally informative approach is the application of specific protein digestion followed by separation and tandem mass spectrometry of the products. This bottom-up proteomics approach $[18,19]$ is powerful but requires digestion and time consuming separation steps. Top-down protein tandem mass spectrometry [20-22] is particularly attractive for rapid analysis of hemoglobin variants because it avoids digestion altogether by subjecting the intact globin chains directly to tandem mass spectrometry. Of the two globin chains in hemoglobin $A$, the $\beta$-chain has been the subject of most attention [23-26], in part because the majority of hemoglobin variants are $\beta$-chain variants $[27,28]$. However, tandem mass spectrometry of the +11 to +14 charge states of the intact $\alpha$-chain of human apohemoglobin has been reported [29], with particular emphasis placed on the favored 
dissociation between $\mathrm{D}_{75} / \mathrm{M}_{76}$ in the +11 and +12 charge states. Furthermore, tandem mass spectrometry applied to ions of an $\alpha$-globin of mass $18 \mathrm{Da}$ greater than the normal human was able to confirm the presence of $\mathrm{Hb}$ Chicago [30].

The utility of any top-down protein tandem mass spectrometry application is dependent upon the extent and quality of the structural information that can be acquired. Factors known to play important roles in deriving structural information from whole multiply charged proteins include the nature of the activation method, the charge state and polarity of the ion, and mass analyzer characteristics such as mass-to-charge range, mass resolution, and mass measurement accuracy. It is the nature of the ion and the dissociation conditions that determine the potential information available, while the performance characteristics of the mass analyzer [31] determine the extent to which the potential information is extracted via mass measurement. In this report, we describe the charge state dependent dissociation behavior of intact multiplyprotonated apohemoglobin $\alpha$-chain ions over the charge state range of $[\mathrm{M}+4 \mathrm{H}]^{4+}$ to $[\mathrm{M}+20 \mathrm{H}]^{20+}$ under quadrupole ion trap collisional activation conditions. The results reported here complement a similar charge state dependent dissociation study of the $\beta$-chain under similar activation conditions [24]. While the product ions in this study have been analyzed via ion trap resonance ejection [32], the results described here have relevance beyond ion trap tandem mass spectrometry. Electrodynamic ion traps are often coupled with other forms of mass analysis, such as timeof-flight [33-35] and Fourier transform ion cyclotron resonance [36]. Furthermore, ion trap collisional activation is a slow heating method [37] that shares commonalities with sustained off-resonance irradiation (SORI) $[38,39]$ commonly used as a means for collisional activation in Fourier transform ion cyclotron resonance tandem mass spectrometry.

\section{Experimental}

Hemoglobin A was purchased from Sigma Chemical Co. (St. Louis, MO) and was purified by reversed-phase high-performance liquid chromatography on a Hewlett-Packard (Palo Alto, CA) model 1090 system, using an Aquapore RP-300 (7 $\mu \mathrm{m}$ pore size, $100 \times 4.6$ $\mathrm{mm}$ i.d.) column (Perkin-Elmer, Wellesley, MA) operated at $1 \mathrm{ml} / \mathrm{min}$. A linear $60 \mathrm{~min}$ gradient from 0 to $100 \%$ buffer B was used, where buffer A was $0.1 \%$ aqueous TFA and buffer B was (60:40) acetonitrilewater containing $0.09 \%$ TFA. The column was maintained at a constant temperature of $40{ }^{\circ} \mathrm{C}$. The absorbance was monitored at $215 \mathrm{~nm}$. The collected fractions were lyophilized and dissolved in $1 \mathrm{ml}$ of water for a concentration of $1 \mathrm{mg} / \mathrm{ml}$. Samples were prepared in either aqueous $1 \%$ acetic acid or 50:50 methanol/water with $1 \%$ acetic acid adjusted to a final concentration of $5-10 \mu \mathrm{M}$ before introduction into the mass spectrome- ter. Samples were ionized using home-built nanoelectrospray emitter set-up. Borosilicate glass capillaries (1.5 mm o.d., $0.86 \mathrm{~mm}$ i.d.) were pulled to form nanospray emitters using a P-87 Flaming/Brown type micropipet puller (Sutter Instruments, Novato, CA). A stainless steel wire was inserted into the capillary and typically about $1.4-1.6 \mathrm{kV}$ was applied for ionization. The electrospray interface and overall instrumental setup for ion/ion reactions have been described previously [40].

All experiments were performed on a Hitachi (San Jose, CA) M-8000 quadrupole ion trap mass spectrometer. The mass spectrometer was modified [40] to allow introduction of singly charged $\left[\mathrm{M}-\mathrm{F}^{-}\right.$and $[\mathrm{M}-$ $\left.\mathrm{CF}_{3}\right]^{-}$anions, derived from atmospheric sampling glow discharge of 1,3-perfluorodimethylcyclohexane (PDCH) [41], into the ion trap through a hole in the ring electrode, as originally described by Stephenson et al. [42]. Typical precursor ion accumulation times were about a few hundred milliseconds. Except for the highest charge states, which were directly subjected to ion isolation and subsequent collisional activation, ion parking [43] was used to concentrate precursor ions by converting higher charge state ions into the charge state of interest via ion/ion proton transfer reactions. Isolation of ions was accomplished using the Hitachi instrument's filtered noise fields (FNF) and by raising the amplitude of the radio frequency signal applied to the ring electrode of the ion trap to eject unwanted ions. An external waveform generator (model 33120A, Agilent, Palo Alto, CA) was used to apply a single frequency resonance excitation voltage to the endcaps for $300 \mathrm{~ms}$ (75-375 mV, depending upon charge state, with the rf amplitude adjusted to allow a resonance ejection frequency of $65-70 \mathrm{kHz}$ for each charge state) to induce CID. Adjustment of the resonance excitation amplitude was done to result in similar overall precursor ion dissociation rates for all charge states. The amplitude of the resonance excitation voltage is a major factor in determining the effective temperature of the fragmenting ions [37]. For whole protein ions, the major overall effect of altering the resonance excitation voltage is to change the dissociation rate of the precursor ion. However, over the relatively small rate range sampled (i.e., $10-100 \mathrm{~s}^{-1}$ ), changes in the relative rates of the competing dissociation channels have been found to be modest for all proteins studied systematically to date. Product ion spectra were acquired via resonance ejection [32] with the frequency determining the mass-to-charge range of the scan. In most cases, ion/ion proton transfer reactions were used after CID to convert most of the product ions to singly charged species to simplify spectral interpretation [44]. The spectra recorded after these ion/ion reactions are referred to as post-ion/ion product ion spectra.

Post-ion/ion product ion spectra were calibrated using the $[\mathrm{M}+\mathrm{H}]^{+},[\mathrm{M}+2 \mathrm{H}]^{2+}$, and $[\mathrm{M}+3 \mathrm{H}]^{3+}$ charge states of hemoglobin A ions formed by ion/ion reactions in the absence of collisional activation. Prod- 


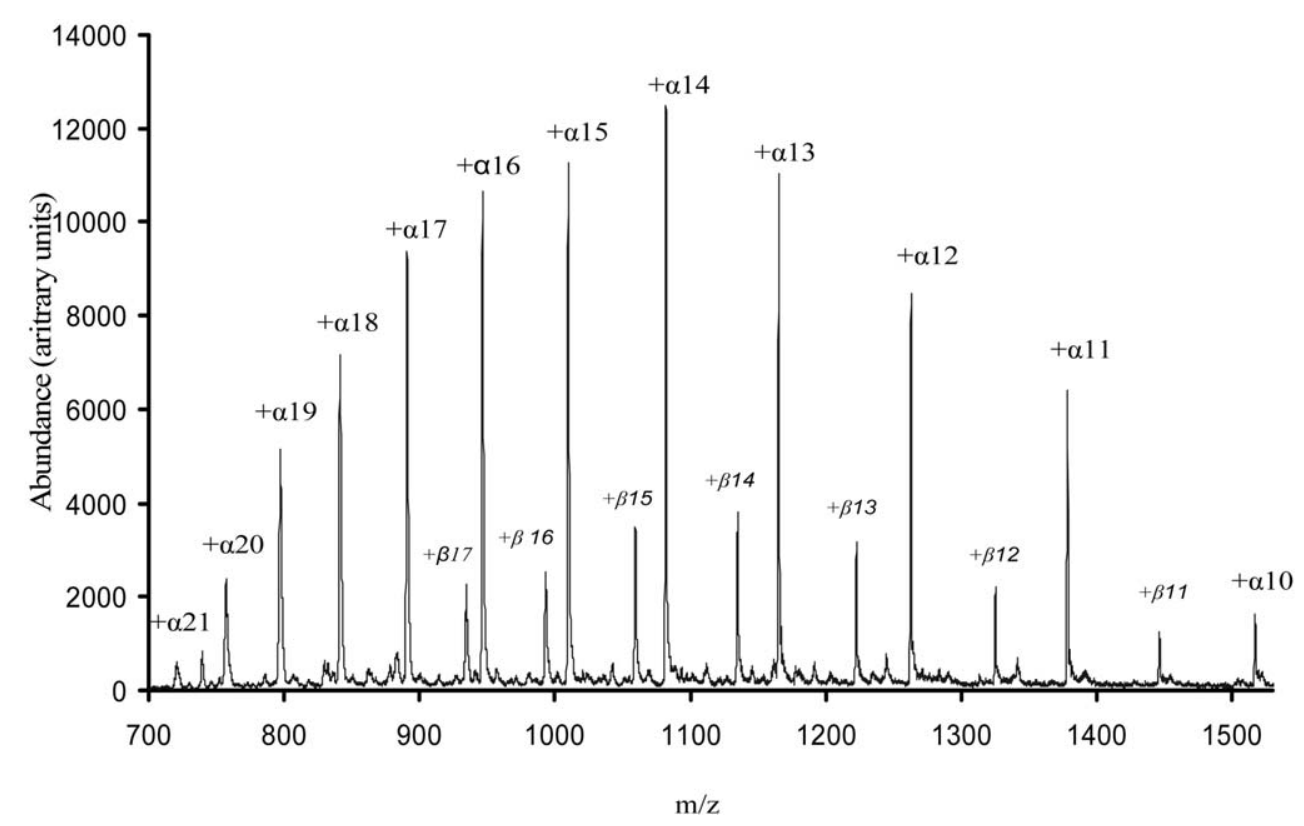

Figure 1. Nanoelectrospray mass spectrum of hemoglobin A from a 50:50 methanol:water solution with $1 \%$ acetic acid.

uct ion assignments have been restricted to b-type and y-type ions, which are the commonly observed fragment types from even-electron peptide and protein ion dissociations under low-energy collisional activation conditions $[45,46]$. In some instances, particularly in the singly charged high mass region of the spectra, both b-type and y-type ions fall within the mass uncertainty of a particular product ion $( \pm 5 \mathrm{Da})$. In some cases, only the assignment deemed more likely is provided. This is generally based on the appearance of complementary ions, fragmentation at a site known to be favored from previous whole protein dissociation studies (e.g., C-terminal to Asp, N-terminal to Pro, C-terminal to Lys), or the appearance of the ion in a series of peaks suggestive of fragmentation along a contiguous series of residues. When no clear criterion is apparent, both possibilities are listed in the format $\mathrm{b}_{\#}{ }^{\mathrm{n}+} / \mathrm{y}_{\#} \mathrm{m+}$, where the number symbol represents the relevant assignment according to conventional peptide fragment ion nomenclature $[47,48]$. A table listing measured and predicted masses for the assigned cleavages is provided in the Supplementary Material section (which can be found in the electronic version of this article).

\section{Results and Discussion}

The nanoelectrospray mass spectrum of hemoglobin A obtained from a 50:50 methanol/water solution with 1\% acetic acid (pH measured to be 3.2) is shown in Figure 1. Under these conditions, the total ion signal from the $\alpha$-chain is significantly greater than that of the $\beta$-chain, as previously observed in a study directed to the fragmentation behavior of the $\beta$-chain ions [24]. The greater response for the $\alpha$-chain is presumably due to its greater basicity $(\alpha$-chain $\mathrm{pI}=8.7, \beta$-chain $\mathrm{pI}=6.8)$ because both chains coeluted in the chromatographic clean-up step. While both proteins are expected to be positively charged under these solution conditions, it has been observed that the greatest positive ion electrospray responses are observed when the solution $\mathrm{pH}$ is roughly 5 units lower than the protein pI [49]. For this study, this discrimination in ionization yield is advantageous in that most of the excess charge of the nanospray droplets is partitioned into the $\alpha$-chain ions.

The $\alpha$-chain of human hemoglobin is comprised of 141 amino acids (molecular weight $=15,126.4 \mathrm{Da}$ ) with 27 nominal basic sites ( 3 arginine residues, 10 histidine residues, 13 lysine residues, and the N-terminus) and 13 nominal acidic sites ( 8 aspartic acid residues, 4 glutamic acid residues, and the C-terminus). The primary sequence of the protein is given in Scheme $\mathbf{1}$, which also includes a summary of the identities of the products observed from amide bond cleavages summed over all charge states studied, as discussed further below.

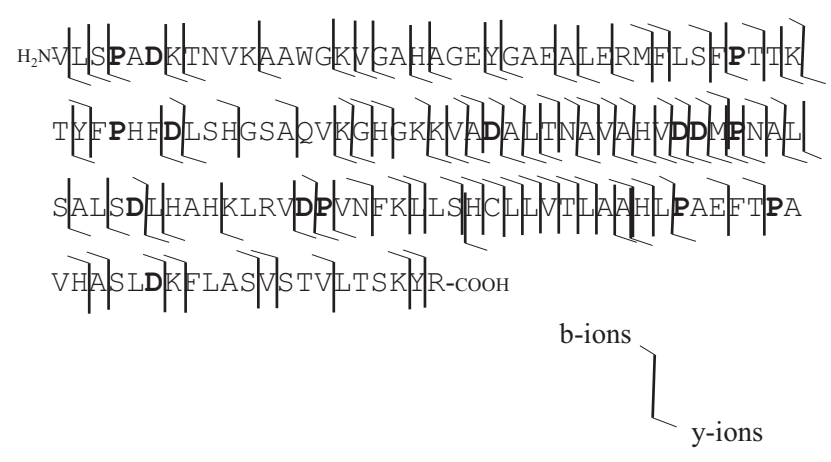

Scheme 1. Primary sequence of human hemoglobin $\alpha$-chain with a summary of observed cleavage sites. 
Previous systematic studies of whole protein cation dissociation studies have indicated that parent ion charge plays a major role in determining favored dissociation channels under ion trap collisional activation conditions [24, 46, 50-54]. While the dissociation behavior of every protein is unique in some ways, several general chargestate-dependent dissociation trends have been observed. For example, it has been noted that the lowest charge states tend to show extensive losses of small neutral molecules, such as water and ammonia. This behavior is believed to arise from low-energy, low-frequency reactions that can arise when the charge sites are highly solvated by other basic sites within the protein. The charge state at which this behavior becomes prominent is protein dependent, but all proteins studied to date show this general tendency. As the charge state increases above those that show predominantly small molecule loss, another essentially universal tendency is noted, viz., cleavage C-terminal to aspartic acid residues. This phenomenon is well-known for relatively low charge state peptide ions [55-57] as well as for protein ions and was highlighted in the early work involving SORI CID of particular charge states of human hemoglobin $\alpha$-chain [29]. As the charge state increases further, the likelihood increases for the observation of cleavages at other amino acid residues, which are termed non-specific cleavages because they tend not to be particularly dependent on side-chain identity. The widest array of cleavages tends to be observed in these ions. At still higher charge states, the diversity of cleavage reactions often decreases and the most abundant dissociation channels are least amenable to prediction. However, cleavages $\mathrm{N}$-terminal to proline residues, another common reaction in peptide ions [58], are often prominent, although they are frequently observed at lower charge states as well. These overall trends have been rationalized on the basis of proton mobility arguments arising from peptide ion dissociation studies [59, 60]. Small molecule losses and C-terminal acidic residue cleavages are not expected to require free intramolecular proton transfer whereas non-specific cleavages are expected to be facilitated by the availability of mobile protons. Proton mobility is expected to be restricted at both low and very high charge states. At low charge states, this restriction results from proton localization due to strongly basic sites and intramolecular solvation and at high charge states, proton mobility is restricted due to electrostatic effects. These general trends provide a context within which the dissociation behavior of the hemoglobin $\alpha$-chain ions can be regarded.

\section{Human Hemoglobin $\alpha$-Chain $[\mathrm{M}+4 \mathrm{H}]^{4+}-[\mathrm{M}+13 \mathrm{H}]^{13+}$}

At charge states below $[\mathrm{M}+4 \mathrm{H}]^{4+}$, it was difficult to fragment the parent ions without significant ion ejection due to the relatively shallow trapping well-depths that could be effected in the ion trap. Furthermore, small molecule losses dominated the fragmentation that was observed. Therefore, the discussion begins with the charge states that tended to show dominant cleavages C-terminal to acidic residues. A relatively wide range of charge states is grouped together here because all these parent ions showed dominant cleavage C-terminal to aspartic acid residues. However, there were significant differences in the relative contributions of these channels as well as differences in the identities of other contributing channels, depending upon charge state. The post ion/ion reaction product ion spectra of the $[\mathrm{M}+4 \mathrm{H}]^{4+}$ and $[\mathrm{M}+6 \mathrm{H}]^{6+}$ parent ions over the range of $m / z 3500-15,200$ are shown in Figure 2a and b, respectively, to illustrate both commonalities and differences for charge states that differ relatively little in absolute charge. Both charge states show evidence for cleavages at $\mathrm{D}_{6} / \mathrm{K}_{7}\left(\mathrm{y}_{135}\right), \mathrm{D}_{47} / \mathrm{L}_{48}\left(\mathrm{~b}_{47} / \mathrm{y}_{94}\right)$, $\mathrm{D}_{64} / \mathrm{A}_{65}\left(\mathrm{~b}_{64} / \mathrm{y}_{77}\right), \mathrm{D}_{74} / \mathrm{D}_{75}\left(\mathrm{~b}_{74} / \mathrm{y}_{67}\right), \mathrm{D}_{75} / \mathrm{M}_{76}\left(\mathrm{~b}_{75} / \mathrm{y}_{66}\right)$, $\mathrm{D}_{85} / \mathrm{L}_{86}\left(\mathrm{~b}_{85} / \mathrm{y}_{56}\right), \mathrm{D}_{94} / \mathrm{P}_{95}\left(\mathrm{~b}_{94} / \mathrm{y}_{47}\right)$, and $\mathrm{D}_{126} / \mathrm{K}_{127}\left(\mathrm{~b}_{126}\right)$, which represents all of the possible C-terminal aspartic acid cleavages. In each case, the $\mathrm{D}_{94} / \mathrm{P}_{95}$ cleavage channel gives rise to the most signal. In addition, both parent ion charge states show a moderately prominent product that is tentatively assigned as cleavage at $\mathrm{L}_{80} / \mathrm{S}_{81}$ to give the $\mathrm{y}_{61}$ ion. The $b_{62}$ ion, which would arise from cleavage at $\mathrm{V}_{62} / \mathrm{A}_{63}$, also falls within the mass accuracy of the measurement. However, the absence of a complementary fragment ion makes either assignment open to question.

The $[\mathrm{M}+4 \mathrm{H}]^{4+}$ parent ion is unique in that it is the only charge state that shows no clear evidence for cleavage at $\mathrm{L}_{113} / \mathrm{P}_{114}\left(\mathrm{~b}_{113} / \mathrm{y}_{28}\right)$. This cleavage eventually becomes the most dominant process at high charge states (see below) and is consistent with $\mathrm{N}$-terminal proline cleavages showing some enhancement in the presence of N-terminal leucine [58]. This is one of the two principle differences in the fragmentation of these two charge states. The other is the presence of a relatively broad signal that corresponds to a loss of roughly $72 \mathrm{Da}$ in the data for the $[\mathrm{M}+6 \mathrm{H}]^{6+}$ ion. The width of the peak also suggests that additional small molecule losses also contribute. In fact, this signal may arise from multiple small molecule losses. However, multiple small molecule losses do not typically give rise to a signal that is clearly resolved from the precursor ion. A similar signal was also noted for the $[\mathrm{M}$ $+5 \mathrm{H}]^{5+}$ and $[\mathrm{M}+7 \mathrm{H}]^{7+}$ precursor ions but not for any other charge states. A possible interpretation of this signal is that it arises from immonium ion loss from the $\mathrm{N}$-terminal valine residue [61]. The appearance of a signal that corresponds to the loss of a charged species of $\mathrm{m} / \mathrm{z}$ 70-75 in the pre-ion/ion product ion spectra (data not shown) is consistent with this interpretation.

As the precursor ion charge state increases further, the contribution of the $D_{75} / M_{76}$ cleavage noted previously [29] increases to the point where it dominates the spectra for the $[\mathrm{M}+8 \mathrm{H}]^{+}-[\mathrm{M}+11 \mathrm{H}]^{12+}$ precursor ions. An illustrative example is provided in Figure 3, which shows the post-ion/ion product ion spectrum of the $[\mathrm{M}+10 \mathrm{H}]^{10+}$ ion.

This cleavage becomes so dominant that the extent of structural information available from these charge states is lower than from either higher or lower charge states. 

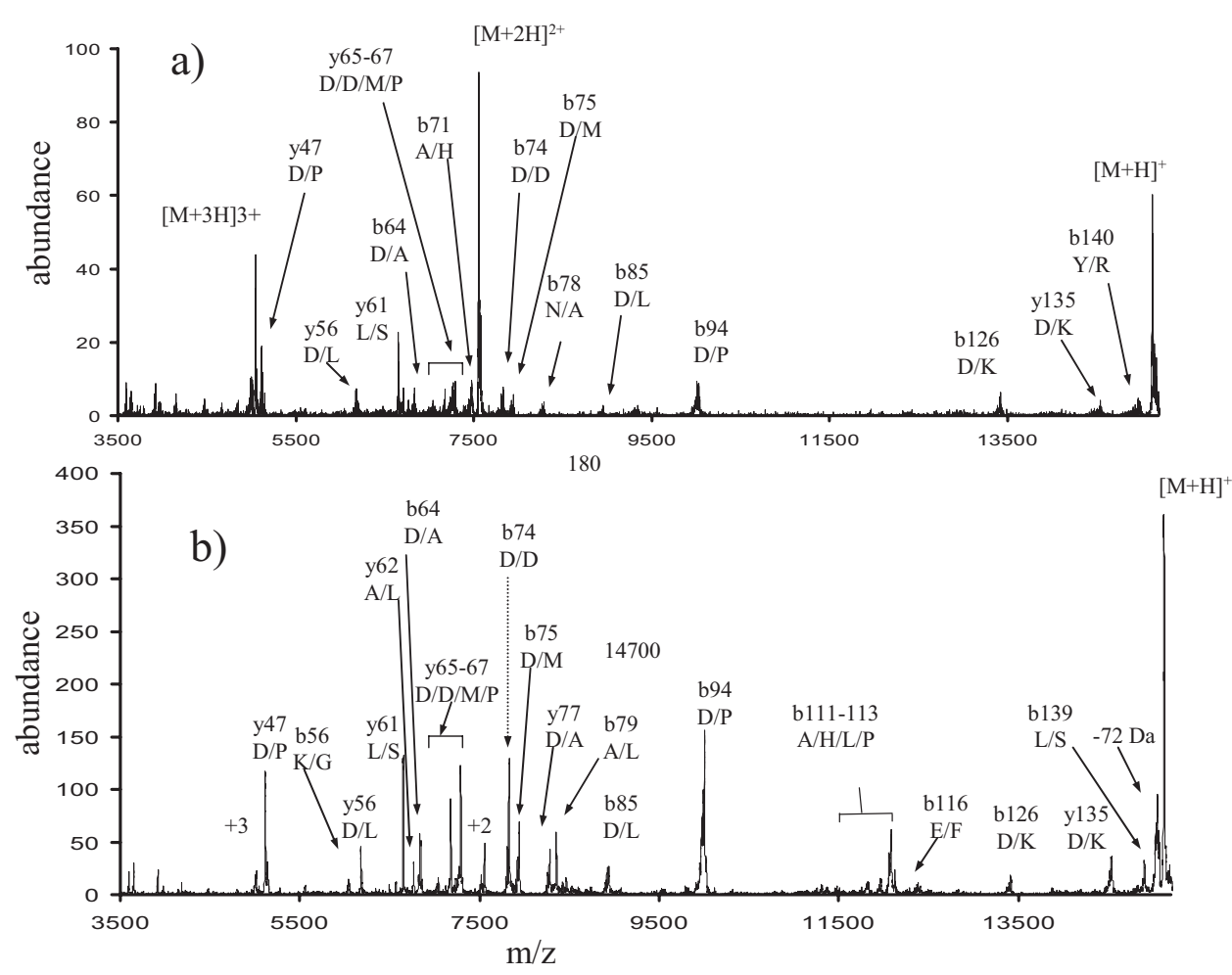

Figure 2. (a) Post-ion/ion MS/MS of $[\mathrm{M}+4 \mathrm{H}]^{4+}$ of $\mathrm{Hb} \alpha$-chain at an activation frequency of 69.0 $\mathrm{kHz}$ and resonance excitation amplitude of $366.0 \mathrm{mV}$. (b) Post-ion/ion MS/MS of $[\mathrm{M}+6 \mathrm{H}]^{6+}$ of $\mathrm{Hb}$ $\alpha$-chain A at frequency of $68.7 \mathrm{kHz}$ and resonance excitation amplitude of $208.3 \mathrm{mV}$.

Nevertheless, a few new fragmentation channels are observed to grow into the spectra as the charge state increases, which primarily arise from cleavages C-terminal to lysine residues. In the case of the $[\mathrm{M}+10 \mathrm{H}]^{10+}$ precursor ion, examples are found in the products that arise from $\mathrm{K}_{139} / \mathrm{Y}_{140}\left(\mathrm{~b}_{139}\right), \mathrm{K}_{56} / \mathrm{G}_{57}\left(\mathrm{y}_{85}\right)$, and $\mathrm{K}_{7} / \mathrm{T}_{8}\left(\mathrm{y}_{134}\right)$.
As the precursor ion charge state increases from +10 to +13 , several trends are noted that can be illustrated with the data for the $[\mathrm{M}+12 \mathrm{H}]^{12+}$ ion, as shown in Figure 4.

First, the C-terminal aspartic acid cleavages continue to be major contributors but there is a consistent de-

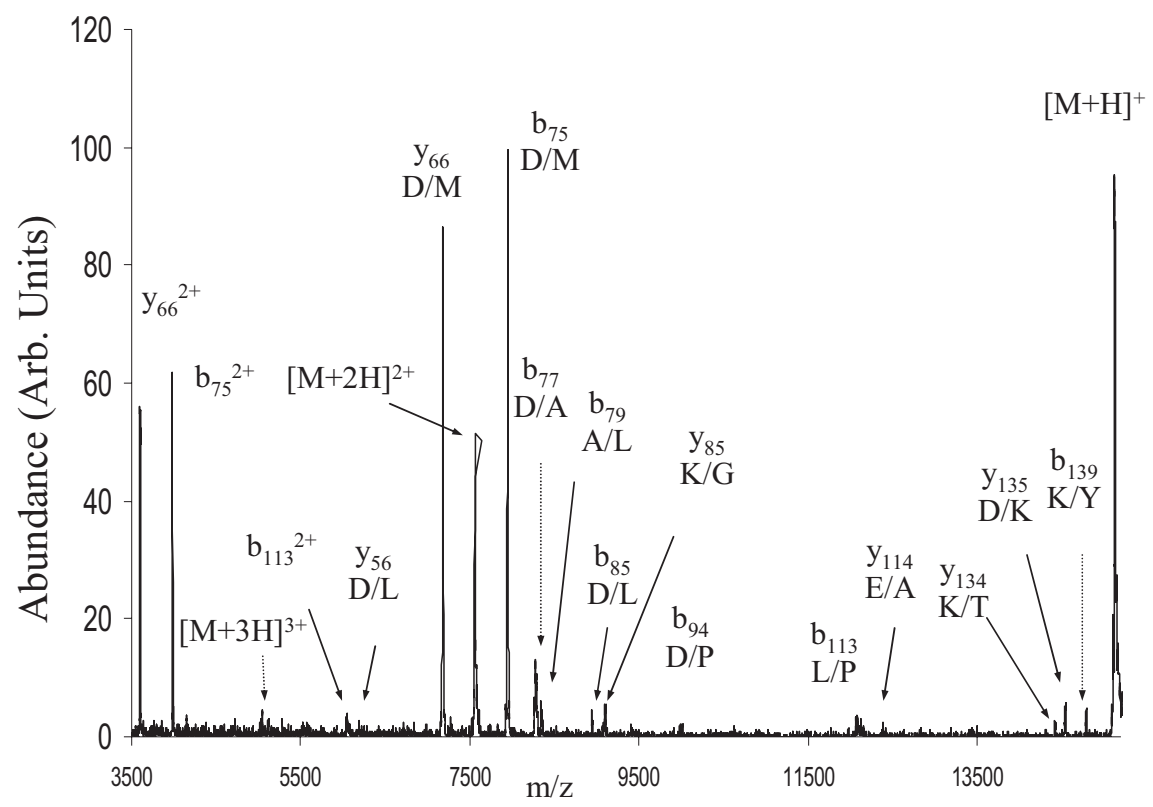

Figure 3. Post-ion/ion product ion spectrum of the $[\mathrm{M}+10 \mathrm{H}]^{10+}$ precursor of $\mathrm{Hb} \alpha$-chain $(134.0 \mathrm{mV}$, $68.6 \mathrm{kHz})$. 


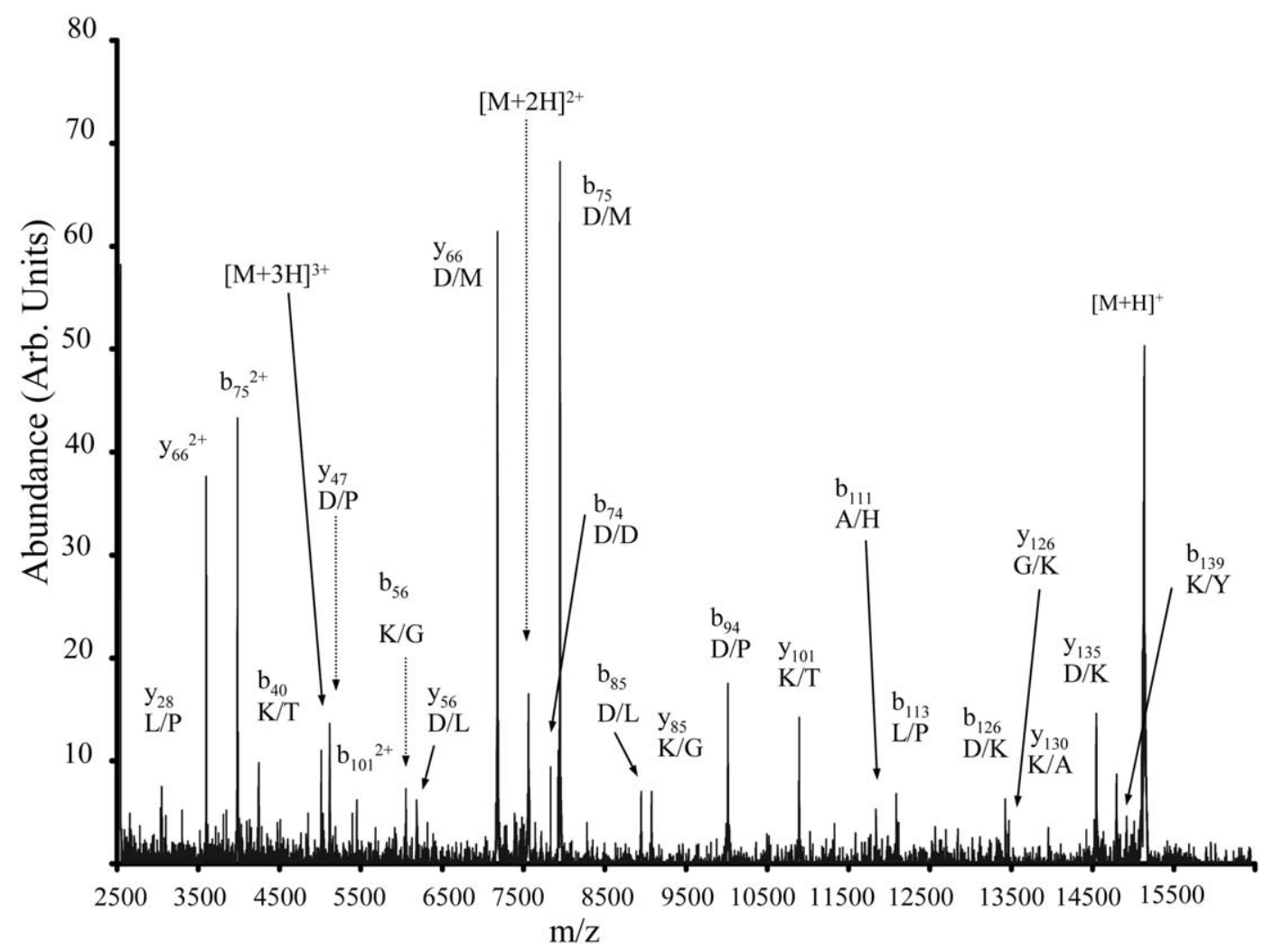

Figure 4. Post-ion/ion product spectrum of the $[\mathrm{M}+12 \mathrm{H}]^{12+} \mathrm{Hb} \alpha$-chain precursor ion (119.0 $\mathrm{mV}$, frequency of $68.3 \mathrm{kHz}$ ).

crease in the extent to which the $D_{75} / M_{76}$ cleavage dominates the spectrum. The $\mathrm{D}_{94} / \mathrm{P}_{95}\left(\mathrm{~b}_{94} / \mathrm{y}_{28}\right)$ cleavage, in fact, becomes the most abundant fragmentation channel in the $[\mathrm{M}+13 \mathrm{H}]^{13+}$ ion. Second, the $\mathrm{L}_{113} / \mathrm{P}_{114}$ $\left(b_{113} / y_{28}\right)$ channel shows a consistent increase in relative contribution. And third, in addition to contributions from a greater number of channels than is observed for the $[\mathrm{M}+8 \mathrm{H}]^{8+}$ to $[\mathrm{M}+11 \mathrm{H}]^{11+}$ precursor ions, the $[\mathrm{M}+12 \mathrm{H}]^{12+}$ and $[\mathrm{M}+13 \mathrm{H}]^{13+}$ charge states show significantly more "chemical noise" in the product ion spectra. This is not due to fewer precursor ions available for activation. Rather, this arises largely from contributions from many low abundance products from many reaction channels. The $[\mathrm{M}+12 \mathrm{H}]^{12+}$ and $[\mathrm{M}+$ $13 \mathrm{H}]^{13+}$ charge states, therefore, show some characteristics usually ascribed to "intermediate" charge states in that there is greater evidence for a degree of proton mobility via the appearance of a greater variety of dissociation channels than is observed with the lower charge states.

\section{Human Hemoglobin $\alpha$-Chain}

$[\mathrm{M}+14 \mathrm{H}]^{14+}-[\mathrm{M}+2 \mathrm{OH}]^{20+}$

The $[\mathrm{M}+14 \mathrm{H}]^{14+}-[\mathrm{M}+20 \mathrm{H}]^{20+}$ precursor ion charge state range is distinguished from the lower charge states by the fact that the C-terminal aspartic acid cleavages no longer dominate the spectra. The $[\mathrm{M}+14 \mathrm{H}]^{14+}$ to $[\mathrm{M}+16 \mathrm{H}]^{16+}$ charge states are similar to the $[\mathrm{M}+12 \mathrm{H}]^{12+}$ and $[\mathrm{M}+13 \mathrm{H}]^{13+}$ charge states in that they tend to show contributions from a relatively wide array of dissociation channels. However, the most dominant channel, and one that makes a significant contribution to all of the higher charge states, is the cleavage at $\mathrm{L}_{113} / \mathrm{P}_{114}$. The $\mathrm{D}_{75} / \mathrm{M}_{76}$ cleavage continues to contribute in the $[\mathrm{M}+14 \mathrm{H}]^{14+}$ to $[\mathrm{M}+16 \mathrm{H}]^{16+}$ charge states but to decreasing degree. These tendencies are illustrated in the data for the $[\mathrm{M}+14 \mathrm{H}]^{14+}$ precursor ion, as shown in

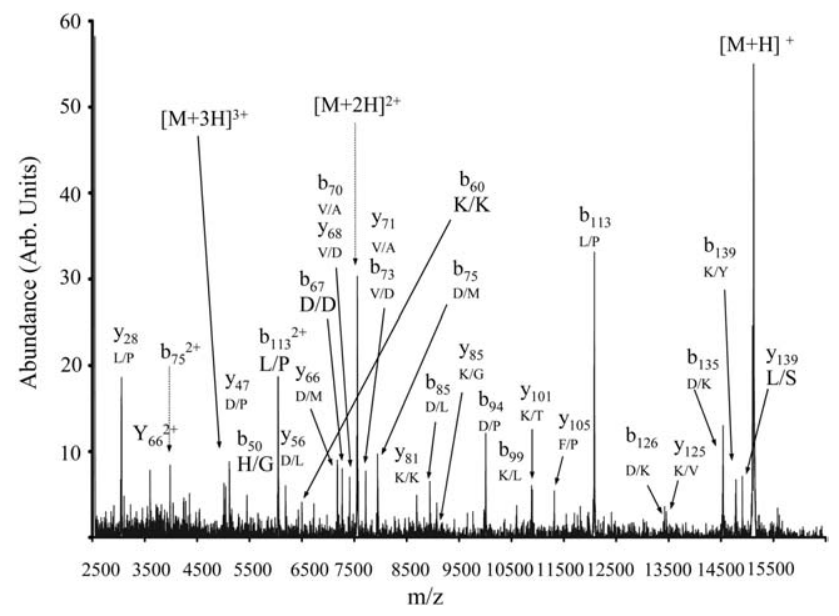

Figure 5. Post-ion/ion product spectrum of the $[\mathrm{M}+14 \mathrm{H}]^{14+}$ $\mathrm{Hb} \alpha$-chain precursor ion $(107.0 \mathrm{mV}$, frequency of $68.0 \mathrm{kHz})$. 

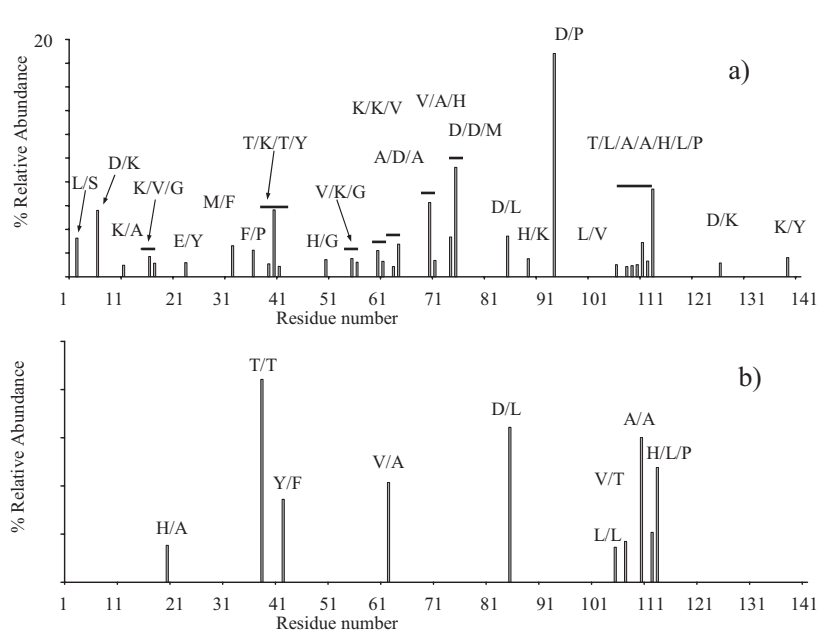

Figure 6. Summed b- and y-ion plots derived from the product ion spectra of the (a) $[\mathrm{M}+13 \mathrm{H}]^{13+}$ and (b) $[\mathrm{M}+20 \mathrm{H}]^{20+}$ precursor ions of $\mathrm{Hb} \alpha$-chain.

Figure 5. This charge state shows, for example, several N-terminal proline cleavages, in addition to the $\mathrm{L}_{113} / \mathrm{P}_{114}$ dissociation, as well as evidence for cleavages C-terminal to several lysine residues, as has been noted for intermediate charge states of other proteins [51].

For the charge states higher than $[\mathrm{M}+16 \mathrm{H}]^{16+}$, the $\mathrm{D}_{75} / \mathrm{M}_{76}$ cleavage no longer contributes to the spectra. Furthermore, fewer dissociation channels are observed and those that are, with the exception of N-terminal proline cleavages, tend not to be "preferred" cleavages, such as C-terminal aspartic acid or lysine residue cleavages. This overall behavior is consistent with high charge states of other proteins examined systematically as a function of charge state in that the dissociation behavior of the highest charge states show the behavior that is least given to generalization.

\section{The Hb $\alpha$-Chain Dissociation Map}

The data of Figures 2-5 show the directly collected product ion spectra and were shown, in part, to provide an indication of the quality of the data. The structural information inherent in the data, however, is more readily visualized when data are presented as summed b- and y-type abundances for complementary ion pairs and plotted as a function of residue number. Examples of plots of this type are shown in Figure 6, which include dissociation data for the $[\mathrm{M}+13 \mathrm{H}]^{13+}$ and $[\mathrm{M}$ $+20 \mathrm{H}]^{20+}$ parent ions.

These plots were generated by including all product ion abundances greater than $5 \%$ of that of the most abundant product ion. The abundances of all of the included product ions were summed to $100 \%$, and the abundances of the summed complementary ions associated with a given dissociation channel were plotted relative to the total product ion abundance. In the case of the data of Figure 6, clearly the $[\mathrm{M}+13 \mathrm{H}]^{13+}$ ion yields more extensive primary sequence information than does the $[\mathrm{M}+20 \mathrm{H}]^{20+}$, which is consistent with the preceding discussion regarding proton mobility. It is also apparent, however, that many of the cleavages for these two charge states are not held in common. Hence, the structural information inherent in the two plots is largely complementary. A summary of all of the data presented in this format is shown in Figure 7.

A summary of the observed cleavages plotted as summed b- and y-plots as a function of charge state is referred to as a "dissociation map". A total of 88 of the 140 possible amide bond cleavages are represented in the dissociation map, representing roughly $62 \%$ of the sequence. Those channels noted are summarized in the primary sequence given in Scheme $\mathbf{1}$. While a substantial fraction of the sequence is reflected in the totality of the dissociation map, clearly the majority of the product ion signal is represented by a relatively few number of channels.

\section{Conclusions}

Globins are important biomarkers and their primary structures provide important diagnostic information. From the standpoint of minimizing analysis times, the application of whole protein MS/MS is attractive. Clearly, the selection of parent ion charge state(s) for subsequent activation via a slow heating method, such as ion trap collisional activation, is critical in determining the extent of structural characterization possible. In the case of the $\mathrm{Hb} \alpha$-chain, for example, minimal structural information is obtained from activation of the $[\mathrm{M}+8 \mathrm{H}]^{8+}$ to $[\mathrm{M}+11 \mathrm{H}]^{11+}$ precursor ions due to the dominance of the $\mathrm{D}_{75} / \mathrm{M}_{76}$ cleavage. On the other hand, these parent ion charge states might be the best choices if an $\mathrm{MS}^{3}$ strategy involving subsequent activation of the $y_{66}$ or $b_{75}$ ions were to be considered. The extent of

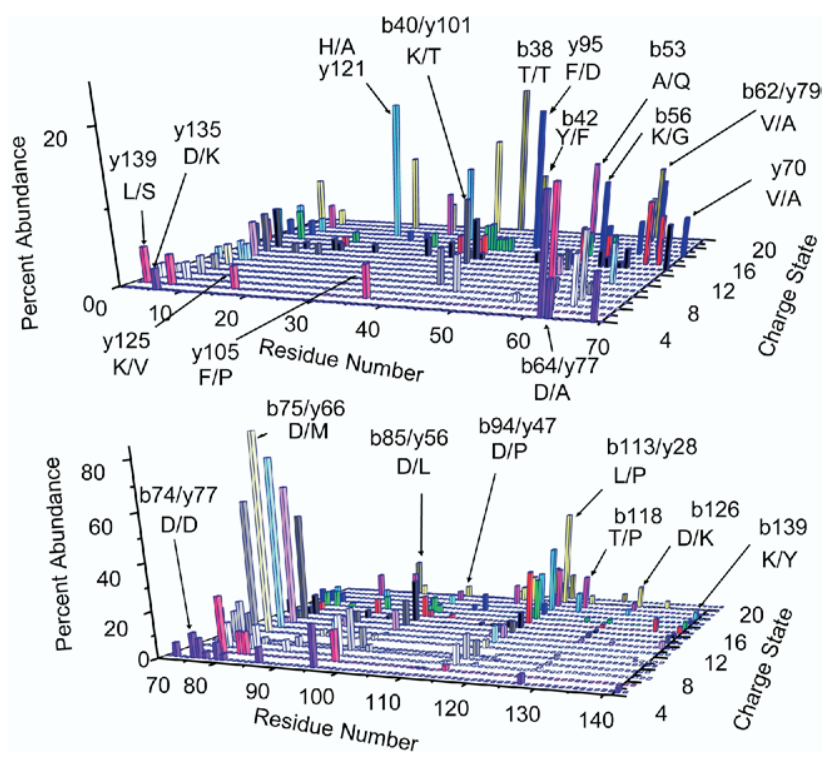

Figure 7. Dissociation map of $\mathrm{Hb} \alpha$-chain cations divided into residue ranges of (a) 1-70 and (b) 71-141. 
structural information available from further activation of these fragments, however, was not examined in this work. No single parent ion charge state was found to provide all of the structural information available from the integration of information from all charge states, although the $[\mathrm{M}+12 \mathrm{H}]^{12+}-[\mathrm{M}+16]^{16+}$ charge states provide the most extensive varieties of amide bond cleavages. Overall, cleavages were noted throughout the protein in the integrated data. Therefore, with the ability to form a wide range of parent ion charge states and to select particular combinations for subsequent activation, based on the known dissociation behavior described herein, should make it possible to localize sites that define various variants. In favorable cases, it should be possible to do so with single residue resolution.

In general, the $\mathrm{Hb} \alpha$-chain cations show charge state dependent dissociation behavior that is consistent with that of most other proteins subjected to similar activation conditions. The most consistently observed tendency across all proteins examined to date is the tendency for C-terminal aspartic acid cleavage at moderately low charge states. This tendency is unusually strong in the case of the $\mathrm{Hb} \alpha$-chain cations. The dominance of a single dissociation channel, as noted with the $\mathrm{D}_{75} / \mathrm{M}_{76}$ cleavage from the $[\mathrm{M}+8 \mathrm{H}]^{8+}{ }_{-}[\mathrm{M}+$ $11 \mathrm{H}]^{11+}$ charge states, is relatively rare. Major contributions from C-terminal aspartic acid cleavages are observed in this globin over a wider range of charge states than for most other proteins studied thus far, despite the relatively few arginine residues available to strongly bind the excess protons. This might suggest a relatively high degree of intramolecular charge solvation over a wide charge state range in this protein.

\section{Acknowledgments}

This research was sponsored by the National Institutes of Health, Institute of General Medical Sciences under grant GM 45372.

\section{References}

1. Wada, Y.; Hayashi, A.; Fujita, T.; Matsuo, T.; Katakuse, I.; Matsuda, H.Structural Analysis of Human-Hemoglobin Variants with Field Desorption Mass Spectrometry.Biochim. Biophys. Acta6672331981241

2. Pucci, P.; Carestia, C.; Fioretti, G.; Mastrobuoni, A. M.; Pagano, L. Protein Fingerprint by Fast Atom Bombardment Mass SpectrometryCharacterization of Normal and Variant Human Hemoglobins. Biochem. Biophys. Res. Commun. 1985, 130, 84-90.

3. Shackleton, C. H. L.; Falick, A. M.; Green, B. N.; Witkowska, H. E. Electrospray Mass-Spectrometry in the Clinical Diagnosis of Variant Hemoglobins. J. Chromatogr. 1991, 562, 175-190.

4. Witkowska, H. E.; Bitsch, F.; Shackleton, C. H. L. Expediting Rare Variant Hemoglobin Characterization by Combined HPLC Electrospray Mass-Spectrometry. Hemoglobin 1993, 17, 227-242.

5. Shackleton, C. H. L.; Witkowska, H. E. Characterizing Abnormal Hemoglobin by MS. Anal. Chem. 1996, 68, 29A-33A

6. Teng, Q.; Harrata, A. K.; Lee, C. S. High Resolution Capillary Isoelectric Focusing Electrospray Ionization Mass Spectrometry for Hemoglobin Variants Analysis. Anal. Chem. 1996, 68, 2482-2487.

7. Nakanishi, T.; Kishikawa, M.; Shimuzu, A.; Hayashi, A.; Inoue, F. Assignment of the Ions in the Electrospray Ionization Mass Spectra of the Tryptic Digest of the Nonderivatized Globin, Covering the Whole Sequence of $\alpha$ - and $\beta$-Chains: A Rapid Diagnosis for Hemoglobinopathy. J. Mass Spectrom. 1995, 30, 1663-1670.

8. Li, M. X.; Wu, J. T.; Liu, L.; Lubman, D. M. The Use of On-Line Capillary Electrophoresis Electrospray Ionization with Detection Via an Ion Trap Storage/Reflectron Time-of-Flight Mass Spectrometer for Rapid Mutation Site Analysis of Hemoglobin Variants. Rapid Commun. Mass Spectrom. 1997, 11, 99-108.
9. Li, L.; Golding, R. E.; Whittal, R. M. Analysis of Single Mammalian Cell Lysates by Mass Spectrometry. J. Am. Chem. Soc. 1996, 118, 11662-11663.

10. Déon, C.; Promé, J. C.; Promé, D.; Francina, A.; Groff, P.; Kalmes, G.; Galactéros, F.; Wajcman, H. Combined Mass Spectrometric Methods for the Characterization of Human Hemoglobin Variants Localized within Alpha T9 Peptide: Identification of $\mathrm{Hb}$ Villeurbanne $\alpha-89$ (FG1) His $\rightarrow$ Tyr. J. Mass Spectrom. 1997, 32, 880-887.

11. Houston, C. T.; Reilly, J. P. Rapid Analysis of Hemoglobin from Whole Human Blood by Matrix-Assisted Laser Desorption/Ionization Timeof-Flight Mass Spectrometry. Rapid Commun. Mass Spectrom. 1997, 11, 1435-1439.

12. Yang, L.; Lee, C. S.; Hofstadler, S. A.; Pasa-Tolic, L.; Smith, R. D. Capillary Isoelectric Focusing Electrospray Ionization Fourier Transform Ion Cyclotron Resonance Mass Spectrometry for Protein Characterization. Anal. Chem. 1998, 70, 3235-3241.

13. Houston, C. T.; Reilly, J. P. Toward a Simple, Expedient, and Complete Analysis of Human Hemoglobin by MALDI-TOFMS. Anal. Chem. 1999, $71,3397-3404$

14. Rai, D. K.; Griffiths, W. J.; Landin, B.; Wild, B. J.; Alvelius, G.; Green, B. N. Accurate Mass Measurement by Electrospray Ionization Quadrupole Mass Spectrometry: Detection of Variants Differing by $<6$ Da from Normal in Human Hemoglobin Heterozygotes. Anal. Chem. 2003, 75, 1978-1982.

15. Rai, D. K.; Griffiths, W. J.; Alvelius, G.; Landin, B. Electrospray Mass Spectrometry: An Efficient Method to Detect Silent Hemoglobin Variants Causing Erythrocytosis. Clin. Chem. 2001, 47, 1308-1311.

16. Rai, D. K.; Alvelius, G.; Landin, B.; Griffiths, W. J. Electrospray Tandem Mass Spectrometry for the Rapid Identification of $\alpha$-Chain Variants. Rapid Commun. Mass Spectrom. 2000, 14, 1184-1194.

17. Daniel, Y. A.; Turner, C.; Haynes, R. M.; Hunt, B. J.; Dalton, R. N. Rapid and Specific Detection of Clinically Significant Haemoglobinopathies Using Electrospray Mass Spectrometry-Mass Spectrometry. Brit. J. Haematol. 2005, 130, 635-643.

18. Aebersold, R.; Goodlett, D. R. Mass Spectrometry in Proteomics. Chem. Rev. 2001, 101, 269-295.

19. Delahunty, C.; Yates, J. R., III. Protein Identification Using 2D-LC-MS/ MS. Methods 2005, 35, 248-255.

20. McLafferty, F. W. High-Resolution Tandem Fourier Transform Mass Spectrometry Above $10 \mathrm{kDa}$. Acc. Chem. Res. 1994, 27, 379-386.

21. Kelleher, N. L. Top-Down Proteomics. Anal. Chem. 2004, 76, 196A-203A.

22. Reid, G. E.; McLuckey, S. A. "Top Down" Protein Characterization by Tandem Mass Spectrometry. J. Mass Spectrom. 2002, 37, 663-675.

23. Light-Wahl, K. J.; Loo, J. A.; Edmonds, C. G.; Smith, R. D.; Witkowska, H. E.; Shackleton, C. H. L.; Wu, C. S. C. Collisionally Activated Dissociation and Tandem Mass-Spectrometry of Intact Hemoglobin $\beta$-Chain Variant Proteins with Electrospray Ionization. Biol. Mass Spectrom. 1993, 22, 112-120.

24. Schaaff, T. G.; Cargile, B. J.; Stephenson, J. L., Jr.; McLuckey, S. A. Ion Trap Collisional Activation of the $(\mathrm{M}+2 \mathrm{H})^{2+}-(\mathrm{M}+17 \mathrm{H})^{17+}$ Ions of Human Hemoglobin $\beta$-Chain. Anal. Chem. 2000, 72, 899-907.

25. Rai, D. K.; Landin, B.; Alvelius, G.; Griffiths, W. J. Electrospray Tandem Mass Spectrometry of Intact $\beta$-Chain Hemoglobin Variants. Anal. Chem. 2002, 74, 899-2102

26. Rai, D. K.; Green, B. N.; Landin, B.; Alvelius, G.; Griffiths, W. J. Accurate Mass Measurement and Tandem Mass Spectrometry of Intact Globin Chains Identify the Low Proportion Variant Hemoglobin LeporeBoston-Washington from the Blood of a Heterozygote. J. Mass Spectrom. 2004, 39, 289-294.

27. http://globin.cse.psu.edu.

28. Clark, B. E.; Thein, S. L. Molecular Diagnosis of Hemoglobin Disorders. Clin. Lab. Hematal. 2004, 26, 159-176.

29. Bakhtiar, R.; Wu, Q.; Hofstadler, S. A.; Smith, R. D. Charge State Specific Facile Gas-Phase Cleavage of Asp ${ }^{75}-\mathrm{Met}^{76}$ Peptide Bond in the $\alpha$-Chain of Human Apohemoglobin Probed by Electrospray Ionization Mass Spectrometry. Biol. Mass Spectrom. 1994, 23, 707-710.

30. Witkowska, H. E.; Green, B. N.; Morris, M.; Shackleton, C. H. L. Intact Protein Electrospray Ionization Tandem Mass Spectrometry Can be the Sole Technique Used for Confirming the Structure of a Variant Hemoglobin. J. Mass Spectrom. 1995, Suppl. S, S111-S115.

31. McLuckey, S. A.; Wells, J. M. Mass Analysis at the Advent of the 21st Century. Chem. Rev. 2001, 101, 571-606.

32. Kaiser, R. E.; Cooks, R. G.; Stafford, G. C.; Syka, J. E. P.; Hemberger, P. H. Operation of a Quadrupole Ion Trap Mass Spectrometer to Achieve High Mass Charge Ratios. Int. J. Mass Spectrom. Ion Processes 1991, 106, 79-115.

33. Michael, S. M.; Chien, M.; Lubman, D. M. An Ion Trap Storage Time-of-Flight Mass Spectrometer. Rev. Sci. Instrum. 1992, 63, 42774284

34. Campbell, J. M.; Collings, B. A., Douglas, D. J. A New Linear Ion Trap Time-of-Flight System with Tandem Mass Spectrometry Capabilities. Rapid Commun. Mass Spectrom. 1998, 12, 1463-1474.

35. Collings, B. A.; Campbell, J. M.; Mao, D. M., Douglas, D. J. A Combined Linear Ion Trap Time-of-Flight System with Improved Performance and MS $^{n}$ Capabilities. Rapid Commun. Mass Spectrom. 2001, 15, 1777-1795.

36. Syka, J. E. P.; Marto, J. A.; Bai, D. L.; Horning, S.; Senko, M. W.; Schwartz, J. C.; Ueberheide, B.; Garcia, B.; Busby, S.; Muratore, T.; Shabanowitz, J.; Hunt, D. F. Novel Linear Quadrupole Ion Trap/FT Mass Spectrometer: Performance Characterization and Use in the Comparative Analysis of Histone H3 Post-Translational Modifications. J. Proteome Res. 2004, 3, 621-626. 
37. McLuckey, S. A.; Goeringer, D. E. Slow Heating Methods in Tandem Mass Spectrometry. J. Mass Spectrom. 1997, 32, 461-474.

38. Gauthier, J. W.; Trautman, T. R.; Jacobson, D. B.Sustained Off-Resonance Irradiation for Collision Activated Dissociation involving Fourier Transform Mass Spectrometry-Collision Activated Dissociation that Emulates Infrared Multiphoton Dissociation. Anal. Chim. Acta. 1991, $246,211-225$.

39. Iavarone, A. T.; Williams, E. R. Collisionally Activated Dissociation of Supercharged Proteins Formed by Electrospray Ionization. Anal. Chem. 2003, 75, 4525-4533.

40. Reid, G. E.; Wells, J. M.; Badman, E. R.; McLuckey, S. A. Performance of a Quadrupole Ion Trap Mass Spectrometer Adapted for Ion/Ion Reaction Studies. Int. J. Mass Spectrom. 2003, 222, 243-258.

41. McLuckey, S. A.; Glish, G. L.; Asano, K. G.; Grant, B. C. Atmospheric Sampling Glow Discharge Ionization Source for the Analysis of Trace Organics in Ambient Air. Anal. Chem. 1988, 60, 2220-2228.

42. Stephenson, J. L., Jr.; McLuckey, S. A. Adaptation of the Paul Trap for Study of the Reaction of Multiply Charged Cations with Singly Charged Anions. Int. J. Mass Spectrom. Ion Processes 1997, 162, 89-106.

43. McLuckey, S. A.; Reid, G. E.; Wells, J. M. Ion Parking During Ion/Ion Reactions in Electrodynamic Ion Traps. Anal. Chem. 2002, 74, 336-346.

44. Stephenson, J. L., Jr.; McLuckey, S. A. Simplification of Product Ion Spectra Derived from Multiply-Charged Parent Ions via Ion/Ion Chemistry. Anal. Chem. 1998, 70, 3533-3544.

45. Tang, X. J.; Thibault, P.; Boyd, R. K. Fragmentation Reactions of Multiply-Protonated Peptides and Implications for Sequencing by Tandem Mass-Spectrometry with Low-Energy Collision-Induced Dissociation. Anal. Chem. 1993, 65, 2824-2834.

46. Reid, G. E.; Wu, J.; Chrisman, P. A.; Wells, J. M.; McLuckey, S. A. Charge State Dependent Sequence Analysis of Protonated Ubiquitin Ions via Ion Trap Tandem Mass Spectrometry. Anal. Chem. 2001, 73, 3274-3281.

47. Roepstorff, P. F.; Fohlman, J. Proposal for a Common Nomenclature for Sequence Ions in Mass Spectra of Peptides. Biomed. Mass Spectrom. 1984, 11, 601-601.

48. Biemann, K. Contributions of Mass Spectrometry to Peptide and Protein Structure. Biomed. Environ. Mass Spectrom. 1988, 16, 99-111.

49. Pan, P.; Gunawardena, H. P.; Xia, Y.; McLuckey, S. A. Nano-Electrospray Ionization of Protein Mixtures: Solution $\mathrm{pH}$ and Protein pI. Anal. Chem. 2004, 76, 1165-1174.
50. Engel, B. J.; Pan, P.; Wells, J. M.; McLuckey, S. A. Charge State Dependent Fragmentation of Gaseous Protein Ions in a Quadrupole Ion Trap: Bovine Ferri-, Ferro-, and Apo-cytochrome c. Int. J. Mass Spectrom. 2002, 219, 171-187.

51. Newton, K. A.; Chrisman, P. A.; Reid, G. E.; Wells, J. M.; McLuckey, S. A. Gaseous Apomyoglobin Ion Dissociation in a Quadrupole Ion Trap: $(\mathrm{M}+2 \mathrm{H})^{2+}-(\mathrm{M}+21 \mathrm{H})^{21+}$. Int. J. Mass Spectrom. 2001, 212, 359-376.

52. Hogan, J. M.; McLuckey, S. A. Charge State Dependent CollisionInduced Dissociation of Native and Reduced Porcine Elastase. J. Mass Spectrom. 2003, 38, 245-256.

53. Schey, K. L.; Cook, L. A.; Hildebrandt, J. D. Ion Trap Tandem Mass Spectrometry of Intact GTP-binding Protein Gamma Subunits. Int. J. Mass Spectrom. 2001, 212, 377-388.

54. Newton, K. A.; Pitteri, S. J.; Laskowski, M.; McLuckey, S. A. Effects of Single Amino Acid Substitution on the Collision-Induced Dissociation of Intact Protein Ions: Turkey Ovomucoid Third Domain. J. Proteome Res. 2004, 3, 1033-1041.

55. Yu, W.; Vath, J. E.; Huberty, M. C.; Martin, S. A. Identification of the Facile Gas-Phase Cleavage of the Asp-Pro and Asp-Xxx Peptide Bonds in Matrix-Assisted Laser Desorption Time-of-Flight Mass Spectrometry. Anal. Chem. 1993, 65, 3015-3023.

56. Qin, J.; Chait, B. T. Preferential Fragmentation of Protonated Gas-Phase Peptide Ions Adjacent to Acidic Amino Acid Residues. J. Am. Chem. Soc. 1995, 117, 5411-5412

57. Tsaprailis, G.; Somogyi, Á.; Nikolaev, E. N.; Wysocki, V. H. Refining the Model for Selective Cleavage at Acidic Residues in Arginine Containing Protonated Peptides. Int. J. Mass Spectrom. 2000, 195, 467-479.

58. Breci, L. A.; Tabb, D. L.; Yates, J. R.; Wysocki, V. H. Cleavage N-Terminal to Proline: Analysis of a Database of Peptide Tandem Mass Spectra. Anal. Chem. 2003, 75, 1963-1971.

59. Dongr3, A. R.; Jones, J. L.; Somogyi, Á.; Wysocki, V. H. Influence of Peptide Composition, Gas-Phase Basicity, and Chemical Modification on Fragmentation Efficiency: Evidence for the Mobile Proton Model. J. Am. Chem. Soc. 1996, 118, 8365-8374.

60. Wysocki, V. H.; Tsaprailis, G.; Smith, L. L.; Breci, L. A. Mobile and Localized Protons: A Framework for Understanding Peptide Dissociation. J. Mass Spectrom. 2000, 35, 1399-1406.

61. Paizs, B.; Suhai, S. Fragmentation Pathways of Protonated Peptides. Mass Spectrom. Rev. 2005, 24, 508-548. 